\title{
我国数字创意产业发展现状及创新方向
}

\author{
黄江杰，汤永川，孙守迁 \\ (浙江大学计算机科学与技术学院, 杭州 310027)
}

\begin{abstract}
摘要: 数字创意产业以科学技术和文化艺术为输入, 以经济价值和文化影响为输出, 是驾驭数字技术的创意内容业和创意制 造业的总称, “十三五” 时期首次被列为国家战略性新兴产业, 为我国产业转型升级、数字经济繁荣发展发挥了重要作用。

本文旨在从宏观层面研究数字创意产业的创新发展方向, 总结我国数字创意产业的发展经验并探讨产业未来发展建议。通过 比较分析国内外数字创意产业的概念、内涵和发展思路, 系统梳理了我国数字创意产业的发展特征、发展状况以及存在问题, 并据此形成了我国数字创意产业的总体发展思路。研究提出了我国数字创意产业持续性创新和发展的四大方向：数字文化创 意技术装备创新、数字文化内容创新、创新设计发展、融合渗透创新发展, 并在数字创意产业的科技攻关、创新机构、平台 企业、人才培养、监管服务、产业聚集等方面提出了对策建议。
\end{abstract}

关键词: 数字创意产业; 技术装备; 文化内容; 创新设计; 融合发展

中图分类号: F120.4 文献标识码: A

\section{Development Status and Innovation Direction of China's Digital Creative Industry}

\author{
Huang Jiangjie, Tang Yongchuan, Sun Shouqian
}

(College of Computer Science and Technology, Zhejiang University, Hangzhou 310027, China)

\begin{abstract}
Digital creative industry is the collective name for the creative content industry and creative manufacturing industry that make effective use of digital technology; it takes science and technology, culture and art as input, and economic value and cultural influence as output. The digital creative industry is identified as one of the national strategic emerging industries for the first time during the 13th Five-Year Plan period, and has played an important role in advancing China's industrial transformation and upgrading and in prospering the digital economy. This paper aims to study the innovation and development direction of the digital creative industry at a macro level, summarizes the development experiences in China, and discusses the future development of the industry. Through a comparative analysis of the concepts and implications of the digital creative industry in China and abroad, the development characteristics, status, and problems of the digital creative industry in China are systematically sorted out, and the overall development ideas of the industry in China are formed accordingly. Furthermore, four major directions is proposed for the continuous innovation and development of China's digital creative industry, namely, digital cultural creative technology and equipment innovation, digital cultural content innovation, innovative design, and integrated innovation. Moreover, countermeasures and suggestions are put forward on the development and expansion of the digital creative industry, in terms of scientific and technological research, innovation institutions, platform enterprises, talent training, supervision services, and industrial clusters.
\end{abstract}

Keywords: digital creative industries; technology and equipment; cultural content; innovative design; integrated development

收稿日期 : 2019-12-23; 修回日期 : 2020-02-26

通讯作者：汤永川, 浙江大学计算机科学与技术学院教授, 研究方向为设计智能与数字创意; E-mail: yctang@zju.edu.cn

资助项目：中国工程院咨询项目“新兴产业发展战略研究（2035）”(2018-ZD-12)

本刊网址： www.engineering.org.cn/ch/journal/sscae 


\section{一、前言}

当前, 人工智能 $(A I)$ 、云计算、物联网、第 五代移动通信 $(5 \mathrm{G})$ 、虚拟现实 (VR)、区块链等数 字技术飞速发展, 推动数字创意产业的变革和壮大, 推动产业发展达到了新高度。发达国家均高度重视 数字创意产业发展, 将之视为抢占未来发展先机、 巩固技术创新优势、扩大软实力和文化影响力的重 要方面。

与国际潮流相呼应, 我国正在大力培育和发展 数字创意产业, 已将其纳入国家战略性新兴产业目 录。数字创意产业成为我国产业发展的战略性方向 之一, 《“十三五” 国家战略性新兴产业发展规划》 提出, 到 2020 年, 形成文化引领、技术先进、链 条完整的数字创意产业发展格局, 相关行业产值 规模将达到 8 万亿元。我国数字创意产业已经进 入高速成长期, 面临着难得的发展机遇, 且增长 潜力巨大。

本文以中国工程院咨询项目 “数字创意产业发 展战略研究 (2035)” 的研究成果为基础, 从数字 创意产业的概念和内涵分析入手, 梳理产业发展的 典型特征, 阐述产业的发展现状并凝练存在的问题, 探讨我国数字创意产业的创新方向, 以期为数字创 意产业的创新发展提供参考。

\section{二、数字创意产业的概念内涵}

关于数字创意产业, 目前国际上尚未形成统一 的定义, 相近的概念有创意产业、版权产业、数字 内容产业、文化创意产业等。发达国家对数字创意 产业的认识、对发展路径的选取有所差异, 例如, 美国通过版权连接整个数字创意产业, 使数字内容 与技术得到协同发展 [1]; 英国以轻量的创意产业 为主, 通过文化驱动产业发展, 突出 “大文化” 综 合管理理念, 适应创意与数字等要素融合的发展趋 势 [2]; 日本与韩国的数字内容业发展势头强劲, 政 府主要通过科技与产业政策来引导相关产业的发展。

为了促进和引领数字创意产业的高质量发展, 我国适时明确了产业内涵及其界定。《“十三五” 国 家战略性新兴产业发展规划》从数字文化创意技术 装备创新提升、数字内容创新发展、创新设计发展、 相关产业融合发展 4 个方面, 对我国数字创意产业
的长远发展进行了顶层规划。《战略性新兴产业分 类 (2018)》全面界定了数字创意产业涉及的国民 经济行业、重点产品与服务, 这为我国数字创意产 业规范、有序和快速发展指明了主攻方向。

具体来说, 我国数字创意产业的细分方向包 括: 设计业、影视与传媒业、数字出版业、动漫游 戏业、在线教育、旅游业、人居环境设计业、时尚 服饰业、体育健康业、玩具业、文化博物业等, 涉 及各细分方向的产业数字化、信息装备与软件业 (见 表 1)。可以看出, 我国数字创意产业的概念与发达 国家存在差异, 更加注重科技、文化、创意的有机 融合与协同发展 [3]。

\section{三、数字创意产业的发展特征}

\section{（一）具有全连接的网络结构}

数字创意产业以数字创意技术和创新设计为基 础支撑, 以文化创意、内容生产、版权利用为发展 核心, 通过融合渗透来带动周边产业领域发展 [3]。 从结构组成来看, 数字创意产业具有全连接的 3 层 网络结构, 即 “ $\mathrm{TD}+4 \mathrm{C}+\mathrm{X}$ ” (见图 1) : (1)输入层 作为基础支撑 (TD), 为数字化及创意化的内容、 产品和服务提供关键技术支撑; (2)中间层作为核心 内容 (4C), 由核心生产和服务构成, 主要供给消 费端高技术的文化创意内容, 形成版权; (3)输出层 包括融合渗透行业 (X), 涵盖玩具业 (Toy)、旅游 业 (Travel)、体育健康业 (Gym) 等多个节点, 借 助数字创意技术和设计的赋能, 通过跨领域的交叉 融合形成新业态和消费点。

数字创意产业通过提升数字创意技术和创新设 计两大基础能力, 推动传统文化创意产业和传统制 造业的转型升级, 拓展形成数字化的创意内容业和 数字化、创意化的制造业。

\section{（二）具有多重的价值输出}

数字创意产业的综合性体现为, 以科学技术 与文化艺术为输入, 以经济价值和文化影响为输 出 [4]。产业具有价值输出的多重性 (见图 2): 通 过对数字技术和文化艺术资源的创新性转化, 打破 现有的产业边界, 催生高效的内容创作方式、传播 渠道和消费形式, 进而提升产业的服务能力和水平; 可实现与其他产业的多维互动和融合发展, 输出经 
表 1 各国数字创意产业的定义与分类对比

\begin{tabular}{|c|c|c|c|}
\hline 国家 & 名称 & 定义 & 分类 \\
\hline 英国 & 创意产业 & $\begin{array}{l}\text { 源于个人创造力、技能和才华的活动, 通过知 } \\
\text { 识产权的生成和利用, 使这些活动发挥创造经 } \\
\text { 济效益和就业的产业 }\end{array}$ & $\begin{array}{l}\text { 广告与市场、建筑、工艺、设计 (产品、平面、时尚)、 } \\
\text { 电影 / 电视 / 视频 / 广播与摄影、信息技术 / 软件与 } \\
\text { 计算机服务、博物馆 / 图书馆 / 画廊、音乐 / 视觉与 } \\
\text { 表演艺术、出版 }\end{array}$ \\
\hline 美国 & 版权产业 & $\begin{array}{l}\text { 从个人创造力、技能和天赋中获取发展动力的 } \\
\text { 企业, 以及通过对知识产权的开发创造潜在财 } \\
\text { 富和就业机会的活动 }\end{array}$ & $\begin{array}{l}\text { 核心版权产业、交叉产业、部分版权产业、边缘 } \\
\text { 支撑产业 }\end{array}$ \\
\hline 日本 & $\begin{array}{l}\text { 数字内容 } \\
\text { 产业 }\end{array}$ & $\begin{array}{l}\text { 加工制作文字、影像、音乐、游戏等信息素材, } \\
\text { 通过媒介流通到用户的信息商品, 包括瞬间可 } \\
\text { 以接收、消费的信息和历经百年拥有大批读者 } \\
\text { 的文学作品 }\end{array}$ & 内容制造产业、休闲产业、时尚产业 \\
\hline 韩国 & $\begin{array}{l}\text { 数字内容 } \\
\text { 产业 }\end{array}$ & $\begin{array}{l}\text { 利用电影、游戏、动漫、唱片、卡通、广播电 } \\
\text { 视等视像媒体或数字媒体等新媒体, 进行储存、 } \\
\text { 流通、亭有的文化艺术内容的总称 }\end{array}$ & $\begin{array}{l}\text { 数字游戏、数字动漫、数字学习、数字内容软件、 } \\
\text { 数字影音、移动增䐈服务和网络服务、数出出版 } \\
\text { 等领域 }\end{array}$ \\
\hline 中国 & $\begin{array}{l}\text { 数字创意 } \\
\text { 产业 }\end{array}$ & 驾驭数字技术的创意内容业和创意制造业 & 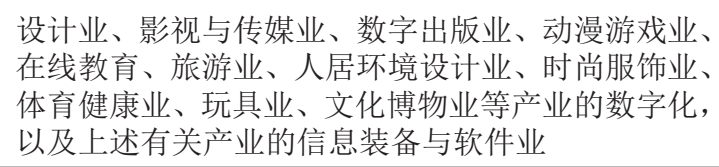 \\
\hline
\end{tabular}

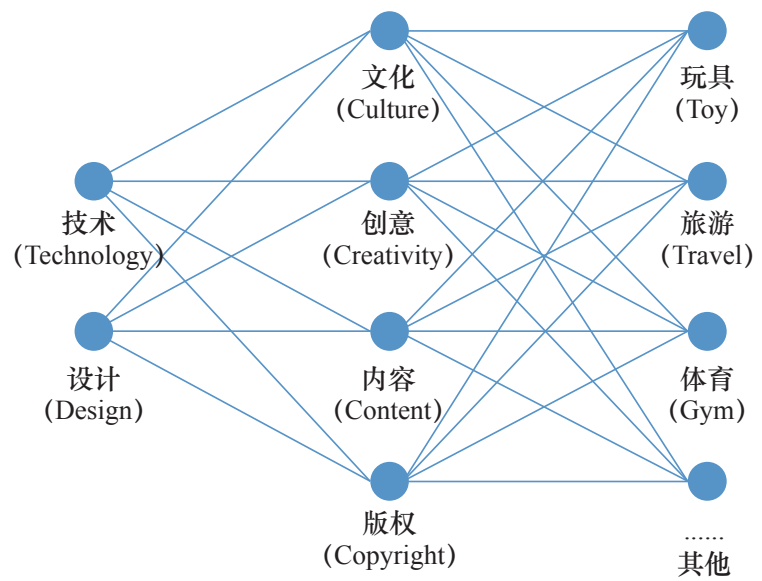

$\underset{\substack{\text { 基础支撑 } \\(\mathrm{TD})}}{+} \underset{(4 \mathrm{C})}{\text { 核心内容 }}+\underset{\text { (X) }}{\text { 融合渗透 }}$

图 1 数字创意产业网络结构全景图

济价值, 为社会经济的发展提供新动能; 可输出优 秀文化内容并发挥正面导向作用, 为我国文化强国 战略提供基本支撑。

\section{（三）需要想象力的引领}

数字创意产业发展取决于想象能力、制造能力 和知识水平 (见图 3), 而想象力起到关键的引领和 组织作用。数字文化创意技术装备的创新提升需要 高想象能力和高制造能力, 数字内容的创新发展需 要高想象能力、高制造能力和高知识水平, 创新设 计的发展需要高想象能力和高知识水平。

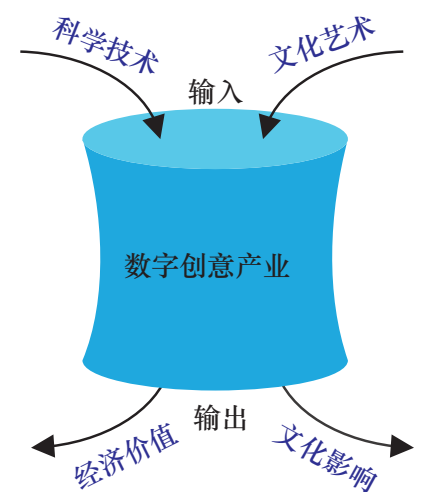

图 2 数字创意产业的多重价值输出

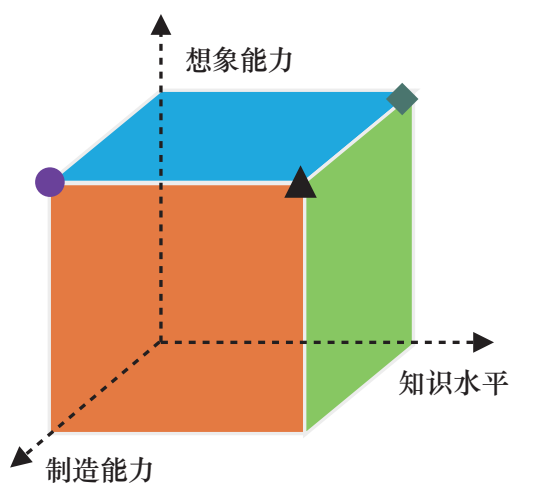

数字文化创意技术装
备创新提升工数字内容创新
发展工程;

图 3 数字创意产业的 3 种能力构成

（四）具有强大的内生动力

随着数字创意产业积极引入新型数字技术, 产 
业结构和商业模式不断变革和创新, 产业边界不确 定性增强且具有强大的内生动力。数字内容服务平 台通过数字技术 (如 $\mathrm{AI}$ ) 应用, 重构了内容创作者 和内容消费者的关系。数字技术企业通过加快布局 数字创意产业, 借助自身技术和平台优势, 推动了 网络文学、影视、游戏、动漫、音乐、体育等产业 领域的快速发展。数字技术推动着数字创意产业的 结构变革，降低了产业结构切换的成本 [5]：创意 内容的制作者可通过数字化平台来充当自己内容的 发行者; 内容发行者可便利地转型成为内容的制作 者; 而创意内容和产品的消费者也可借助于平台型 企业 (如短视频平台), 制作并分享创意内容而成 为内容生产者。

\section{四、数字创意产业发展现状和面临的问题}

\section{（一）整体发展情况}

作为我国战略性新兴产业之一，数字创意产 业有力地推动了国家经济和社会的发展。根据文 化产业的相关统计显示, 2019 年我国规模以上 文化及相关产业实现营业收入 86624 亿元, 比 2018 年增长 $7.0 \%$, 略高于同期我国装备制造业的 发展速度。这表明, 相关产业保持平稳较快增长, 产业结构持续优化。从细分行业来看, 2019 年内 容创作生产和文化消费终端生产行业的营业收入 均超过 1.6 万亿元, 成为产业发展的头部领域; 新 闻信息服务、创意设计服务和文化投资运营行业 的增长率均超过 $10 \%$, 成为产业发展重要的增长 点（见表 2)。

\section{（二）阶段性发展成就}

“十三五” 时期, 在一系列重要政策的推动下, 我国数字创意产业取得了诸多发展成就。

1. 数字文化创意技术装备创新提升

随着 VR、AI、5G、超高清 $(4 \mathrm{~K} / 8 \mathrm{~K})$ 、全息成 像、感知交互等数字技术的飞速发展, 数字文化创 意技术装备朝着更高分辨率、更好交互方式、更多 样媒体形式、更具沉浸感体验的方向创新发展。

在超高清显示技术装备领域, 我国智能超高清 技术、产品、服务和应用协调发展的格局正在形成, 驱动了数字经济的规模化发展和高速扩张。2019年, 先进面板产线 (10.5/11 代) 已实现量产, 面板产能 占全球的 53\%。超高清视频编解码技术和标准走在 世界前列, 具有 AVS3 标准的芯片设计和制作能力, 支持 $8 \mathrm{~K}$ 分辨率和 $120 \mathrm{~Hz}$ 刷新率。超高清 $\mathrm{AI}$ 芯片 研制成功并投入播放器批量应用。4 $\mathrm{K}$ 产业链初步 形成, $4 \mathrm{~K}$ 电视机进入普及阶段, 央视春晚、国家 庆典等重大活动实现了 $4 \mathrm{~K}$ 直播。

在 VR 和增强现实 (AR) 技术装备领域, 产 业发展重点逐步从整机代工转向核心元器件研发, 重点提升网络架构、三维建模、高性能算法等通用 型技术以有效加强软件研发。数字内容供给不断丰 富, 产业链向下游拓展延伸。另外, VR/AR 与 $\mathrm{AI}$ 、 $5 \mathrm{G} 、 4 \mathrm{~K} / 8 \mathrm{~K}$ 等技术进行融合创新, 推动产生新产品、 新技术和新模式。

\section{2. 数字内容创新发展}

近年来, 数字内容产业保持蓬勃发展态势, 成 为引领文化振兴、实施文化强国的重要产业, 构成 了我国数字经济的重要力量。

2018 年, 我国数字出版产业整体收入规模约为

表 2 全国文化及相关产业营业收入情况（2019 年）

\begin{tabular}{lccc}
\hline 行业类别 & 绝对额/亿元 & 比 2018 年增长 $/ \%$ & 占比/\% \\
\hline 新闻信息服务 & 6800 & 23.0 & 7.9 \\
内容创作生产 & 18585 & 6.1 & 21.5 \\
创意设计服务 & 12276 & 11.3 & 14.2 \\
文化传播渠道 & 11005 & 7.9 & 12.7 \\
文化投资运营 & 221 & 13.8 & 0.3 \\
文化娱乐休闲服务 & 1583 & 6.5 & 1.8 \\
文化辅助生产和中介服务 & 13899 & 0.9 & 16.0 \\
文化装备生产 & 5722 & 2.2 & 6.6 \\
文化消费终端生产 & 16532 & 5.5 & 19.1 \\
\hline
\end{tabular}

注: 根据国家统计局发布数据整理。 
8330.8 亿元，同比增长 $17.8 \%$ 。得益于数字技术和 产业政策的持续推进, 传统出版产业的数字化转型 升级更为深入, 数字出版产业在诸多领域继续保持 稳健增长态势 [6]。AI 技术在内容生产领域得到推 广应用, 构成了新的数字内容生产方式。在互联网、 $\mathrm{AI}$ 等技术的推动下, 知识服务行业蓬勃发展, 提供 了优质的知识内容和服务体验, 改变了传统知识生 产与消费的方式。

在数字内容 “走出去” 方面, 截至 2018 年 年底, 我国已成为全球互联网文化娱乐领域的 第二大市场、网络游戏领域的第一大市场; 作为网 络文学创作大国, 我国向海外输出的网络文学作品 超过 11000 部。此外, 直播平台、短视频平台也进 行了全球化布局, 进入了多个国家或地区的应用市 场, 产生了新的内容生产和创作群体, 形成了新的 就业和服务形态。

\section{3. 创新设计发展}

目前, 我国创新设计区域的集聚和辐射格局 基本形成。联合国教科文组织将 “设计之都” “手 工艺与民间艺术之都” “电影之都” “媒体艺术之 都” 等称号授予我国多个城市, 如深圳、上海、北 京、武汉、杭州、苏州、景德镇、青岛、长沙等。 2019 年 10 月, 首届中国 (杭州) 国际智能产品博 览会盛大举行, 全面呈现了数字经济和 $\mathrm{AI}$ 技术的 成果转化、融合带动以及应用进展。

在企业创新设计方面, 诸多重点企业具备了国 际性的竞争力。中国创新设计产业战略联盟成功组 建, 通过联合 “产学研、媒用金” 各方力量和创新 资源, 形成了多元化的技术和服务平台, 为国家创 新设计整体能力提升、创新驱动发展战略实施提供 了基础性和关键性的支持。

\section{（三）存在问题}

数字创意产业作为未来赢得竞争新优势的关键 领域 [7], 尽管近年来一直处于高速发展阶段, 但 发展瓶颈有所显现, 面临的问题不容忽视。

1. 数字文化创意技术装备的创新支撑不足

我国数字文化创意技术与装备领域的技术水平 与发达国家存在一定的差距。(1)在 $4 \mathrm{~K} / 8 \mathrm{~K}$ 领域, 我 国在传输与存储、编解码 / 芯片、显示技术等方面 处于不利地位, 关键技术体系存在短板 [8]; 标准 体系尚未完全建立, 高端产品和关键器件依赖进口;
超高清视频在采集、制作、传输、呈现等环节的协 同创新不足。(2)在 VR 技术装备领域, 近眼显示、 感知交互、渲染处理和内容制作等技术有待进一步 突破; 包含芯片、传感器、显示器件、光学器件等 软硬件在内的系统集成能力存在不足, 高端 VR 整 机设备和感知交互设备较为缺乏。

2. 数字内容创新的整体质量不高

国内在数字内容创作方面的创新能力不足、内 容质量不高、文化内涵不足、精品力作不多、社会 责任感不强等问题相对突出, 应及时扭转趋势, 作 为重点内容予以解决。在软件工具方面, 高端数字 内容制作和设计软件的进口依赖度极高, 不利于数 字创意产业的自主稳定发展。智能内容设计生成是 数字内容生产领域的前沿 [9], 而国外一直在智能 设计技术、系统和平台方面占据主导优势, 这使得 我国在该领域的发展面临重大挑战。

\section{3. 创新设计总体水平不强}

我国创新设计总体水平大而不强, 跨学科协同 和系统集成创新的意愿不强、能力不够, 难以切实 支撑起数字创意产业快速发展的需要。在数字创意 产业的多个领域, 需要融合涉及领域的知识与技术, 对 AI、大数据、云计算、数字感知交互、VR 等前 沿技术进行系统集成和创新应用, 由此实现高层次 的人机协同。而国内在这些方面尚处于起步阶段, 距离先进水平、现实需求也有较大差距。另外, 数 字创意产业面临的优秀人才缺乏现象较为突出, 而 新设计人才的培养又需要一定周期, 这些都制约了 产业的健康发展。

\section{五、数字创意产业的创新发展方向}

着眼未来可以预判, 数字创意产业的发展趋势 表现为: 需求主体与供给主体高度融合, 数字形态 与物理实体高度融合, 技术、装备与文化创意高度 融合。因此, 亟需依托我国在 $\mathrm{AI} 、 5 \mathrm{G}$ 等技术领域 积累的技术优势, 加快数字创意产业技术与装备短 板的技术突破, 科学布局数字创意产业创新体系, 在数字文化创意技术装备、数字文化内容、创新设 计、融合渗透等方向实施重点创新（见图 4)。

\section{（一）数字文化创意技术装备}

数字文化创意技术装备是数字创意产业繁荣发 


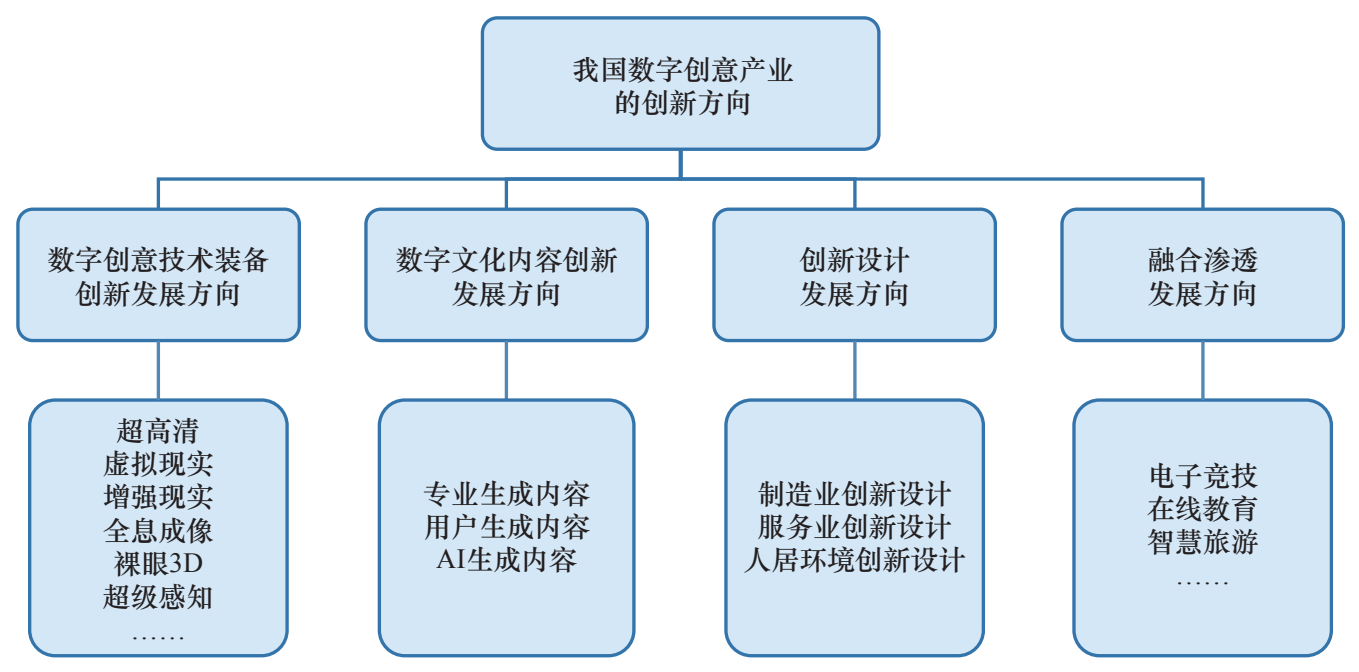

图 4 数字创意产业创新发展内容构成

展的基石, 也是保障优质数字内容供给的关键因素。 $\mathrm{AI} 、$ 大数据、物联网、5G、区块链等通用型数字技 术加速创新发展, 积极改造和重塑了数字内容生产、 分发和消费的模式。 $4 \mathrm{~K} / 8 \mathrm{~K} 、 \mathrm{VR} 、 \mathrm{AR}$ 、全息成像、 裸眼 $3 \mathrm{D}$ 、超级感知等相关技术装备的创新发展, 在为数字内容呈现和体验提供新形式的同时, 也向 数字内容生产提出了更高要求。未来数字创意产业 有望形成 “平台/场景 + 内容” “知识产权 (IP) + 技术” 的新兴商业模式。在创新链和产业链衔接发 展的过程中, 以内容创作、分享为主的平台型企业 有望脱颖而出, 以内容创作、分享为主的大数据和 人工智能类企业也将是发展方向, 支撑构成数字创 意产业的新格局和新生态。

\section{（二）数字文化内容}

数字文化内容在创新发展的进程中分类形成了 专业生产内容 (PGC)、用户生成内容 (UGC) 和 $\mathrm{AI}$ 生成内容 (AIGC) 等创作方式, 促进了业态创新。 未来一段时期, PGC 仍是数字文化内容创作的重要 方式, 如影视综艺行业近年来一直表现出稳定的增 长态势。鉴于我国短视频平台具有移动性、互动性、 碎片化、制作简单、视觉冲击力强的产品特征, 加 之契合了互联网社交和内容消费的需要, UGC 创 作方式将取得快速发展。面对呈指数级增长的文字、 图像、声音、视频等海量的内容数据, 新一代 AI 技术已展现出强大的处理能力和创意能力, AIGC 将成为日益重要的内容生产方式。PGC、UGC 和 $\mathrm{AIGC}$ 的融合应用将是未来数字文化内容创作的必
然途径。此外, 利用 $\mathrm{AI}$ 和计算机图形学 (CG) 进 行虚拟场景和角色生成, 逐渐成为影视网络平台的 核心能力; 将照片与绘画相结合的计算机艺术蓬勃 兴起, 也为产业发展带来新的增长点。

\section{（三）创新设计}

创新设计不仅用于解决人 / 机 / 艺术的问题, 而 且将高效吸收各种新技术 (互联网、大数据和 AI 等), 可以据此开展商业模式创新, 促进不同文化 的交融互鉴。面向传统制造业, 采用创新设计来整 合 AI、VR、大数据、云计算、传感器等技术, 附 加感知功能并提供智能反馈来实现高层次的人 / 机 协同。重点推动高技术服务业和知识密集型服务业 的创新发展, 促进服务业与互联网、物联网的协同 发展和融合发展, 进一步丰富服务内容与形态。面 向人居环境设计服务, 拓展大数据、VR 等技术和理 念的运用, 实现城乡规划、园区和建筑设计、园林 设计、装饰设计等的创新发展。秉持 “企业领衔, 教育跟上” 的方针, 加快推动创新设计教育体系和 创新设计人才培养体系的建设与完善。

\section{（四）融合渗透}

数字创意产业在数字技术的驱动下, 可打破现 有的产业边界, 与其他产业实现多维互动、融合发 展, 进而为经济社会发展提供新动能 [10]。(1)在线 教育是科技、数据、数字内容与教育的相互融合, 出版业、动漫业、玩具业和在线教育的融合则是重 要组成部分; 将 $\mathrm{AI}$ 技术应用到教学环节, 拓展形 
成全方位、多维度的教学应用, 支持 “千人千面” 在线教学; 部分在线教育企业依托作业大数据、学 科大数据、用户大数据, 有望发展成为数据驱动的 $\mathrm{AI}$ 公司。(2)电子竞技是体育、游戏、直播互相融合 的重要方向, 内容输出以游戏企业为主, 传播以各 大直播平台为主，体育方面注重与体育赛事、体育 品牌开展长期合作。(3) “互联网 + 旅游” 的消费模 式逐渐兴起, 智慧旅游成为大众消费娱乐文化产品 的重要内容, 短视频和直播为旅游业提供了强大的 引流能力; 影视、动漫、演艺、文化创意等业态和 旅游业加速融合, 丰富了旅游观光者的消费体验。

\section{六、对策建议}

\section{（一）设立数字创意技术与装备国家科技重大专项}

为整体解决我国数字创意技术与装备领域的关 键核心技术短板与 “卡脖子” 问题, 建议以国家科 技重大专项的形式予以攻关突破。加大数字创意技 术与装备领域的关键核心技术、关键元器件、高端 产品、创新应用、软件平台与工具的研发支持力度, 在推动产业竞争力进入国际第一方阵前列的同时, 为促进我国数字创意产业和数字经济的持续繁荣发 展储备关键技术潜力。

\section{（二）建设数字创意国家工程研究中心}

数字创意产业的发展需要数字创意技术、装备 和数字文化内容的协同创新。建议鼓励和支持在数 字内容创作、技术与装备创新方面具有明显优势的 省份, 如浙江省和广东省牵头组织重点高校、科研 机构和龙头企业, 联合建设数字创意国家工程研究 中心。通过国家工程研究中心的设立运行, 优化数 字创意技术与装备的创新和产业化支撑体系，提升 产业的自主创新能力, 保障产业核心竞争能力和发 展后劲。

\section{（三）培育数字内容创作和知识分享的平台型企业} 采取市场化的方式, 培育一批以数字内容创作、 知识分享为主要形式的平台型企业, 鼓励在线教育、 知识服务、短视频、直播、有声读物、网络文学等 平台企业做大做强, 提高我国优秀文化传播能力和 国际竞争力。鼓励内容平台企业开展数字创作、审 核监管、网络分发、信息安全等技术的自主研发,
推动 $\mathrm{AI}$ 技术的应用落地和深化发展。

\section{（四）加强数字创意产业人才培养}

数字创意产业高端人才稀缺, 主流人才缺口较 大。建议加强数字创意人才的本土化教育培养, 同 步开展国际人才双向交流, 共同构建面向数字文化 内容和数字技术装备的创新设计人才体系。加快实 施一流数字创意学院建设示范项目, 注重艺术、文 化、科技、商业等综合能力锻炼, 提高复合型人才 的培养质量。推行原创作品培育原创人才机制, 完 善原创作品的保护和激励机制, 在数字内容作品创 作初期, 以市场化方式给予创作人员以一定的鼓励, 加强知识产权保护以提高作品创造的积极性。

\section{（五）完善数字创意产业监管和服务体系}

应对形势发展并适当前瞻, 论证制定数字内容 质量监管和评价机制，探讨设立不良信息内容传播 风险评估机构。完善数字内容以及原创设计的版权 和知识产权保护法规, 推进面向智能设计、智能生 成内容的立法建设, 保障数字创意产业的健康有序 发展。探索设立开源服务平台, 建立数字创意产业 评价指标体系, 构建以企业为主体、市场为导向、 “产学研用”协同的创新机制。加快建设跨部门、 跨区域、跨行业的文化资源大数据平台和共享平台, 开展文化资源分类与标识、数字化采集与管理、多 媒体内容知识化加工处理, 支持优秀传统文化资源 的创造性转化和创新性发展。

\section{（六）打造具有国际影响力的数字创意之都}

鼓励北京、上海、深圳、杭州等数字创意资源 丰富的城市, 开展综合性数字创意产业集聚区建设, 推动数字创意与实体经济融合, 打造具有国际影响 力的数字创意之都。拓展数字创意在会展、电子商 务、医疗卫生、教育服务、旅游休闲等领域的应用, 加快体育竞赛、表演产业的转型升级和融合发展, 打造一批高质量、国际化、现代化的旅游目的地。

\section{参考文献}

[1] 潘云鹤, 丁文华, 孙守迁, 等. 数字创意产业发展重大行动计划 研究 [M]. 北京: 科学出版社, 2019.

Pan Y H, Ding W H, Sun S Q, et al. Research on the major action plan for the development of the digital creative industry [M]. Beijing: China Science Publishing \& Media Ltd., 2019. 
[2] Flew T. From policy to curriculum: Drivers of the growth in creative industries courses in the UK and Australia [J]. Creative Industries Journal, 2019, 12(2): 167-184.

[3] 中国工程科技发展战略研究院. 中国战略性新兴产业发展报告 2019 [M]. 北京: 科学出版社, 2018.

Chinese Institute of Engineering Development Strategies. China's strategic emerging industry development report 2019 [M]. Beijing: China Science Publishing \& Media Ltd., 2018.

[4] 中国工程科技发展战略研究院. 中国战略性新兴产业发展报告 2020 [M]. 北京: 科学出版社, 2019.

Chinese Institute of Engineering Development Strategies. China strategic emerging industry development report 2020 [M]. Beijing: China Science Publishing \& Media Ltd., 2019.

[5] Strandgaard P J, Slavich B, Khaire M. Technology and creativity [M]. Cham: Palgrave Macmillan, 2020.

[6] 蔡翔. 传统出版融合发展: 进程、规律、模式与路径 [J]. 出版科 学, 2019, 27(2): 5-14.

Cai X. Integration and development of traditional publishing: Process, law, model and path [J]. Publishing Science, 2019, 27 (2):
$5-14$.

[7] 孙守迁, 闵歆, 汤永川. 数字创意产业发展现状与前景[J]. 包装 工程, 2019, 40(12): 65-74.

Sun S Q, Min M, Tang Y C. Status and prospects of digital creative industry development [J]. Packaging Engineering, 2019, 40 (12): 65-74.

[8] 黄蕴华, 李慧颖, 黄璐艳. 超高清视频产业专利态势分析 [J]. 电 子知识产权, 2019 (7): 76-84.

Huang Y H, Li H Y, Huang L Y. Analysis of the patent situation of the ultra-high-definition video industry [J]. Electronic Intellectual Property, 2019 (7): 76-84.

[9] Tang Y, Huang J, Yao M, et al. A review of design intelligence: progress, problems, and challenges [J]. Frontiers of Information Technology \& Electronic Engineering, 2019, 20(12): 1595-1617.

[10] 陈刚, 宋玉玉. 数字创意产业发展研究 [J]. 贵州社会科学, 2019 (2): 82-88.

Chen G, Song Y Y. Research on the development of digital creative industry [J]. Guizhou Social Science, 2019 (2): 82-88. 